\title{
Strengthening, rehabilitation and widening of the existing arch bridge on national route 7 over the Olifants River, South Africa
}

\author{
Pierre van der Spuy ${ }^{1,2, *}$, and Hennie Niehaus ${ }^{1}$ \\ ${ }^{1}$ Aurecon South Africa (Pty) Ltd, Transportation Unit, Cape Town, South Africa \\ ${ }^{2}$ Stellenbosch University, Civil Engineering Department, Stellenbosch, South Africa
}

\begin{abstract}
This paper describes the rehabilitation of the existing bridge over the Olifants River. The bridge is on National Route 7 near Klawer and dates back to 1957. The defining feature of this elegant bridge is a concrete arch spanning $92.7 \mathrm{~m}$. The existing bridge displayed extensive cracking, failed expansion joints and spall damage to beam soffits. Some columns showed vertical cracks while some foundations presented with horizontal cracks. The arch presented with longitudinal cracks on both the upper and lower surfaces and a previous attempt to fill the cracks proved unsuccessful, as the cracks continued to widen. This paper presents the investigations undertaken to determine the cause for the observed defects as well as the methods employed to rehabilitate the bridge. These measures include strengthening with carbon fibre, coatings, patch repair, replacement of reinforcement, replacement of expansion joints and replacement of parapets. The work commenced early 2016 and was substantially completed mid-2018.
\end{abstract}

\section{Project description}

The South African National Roads Agency Limited (SANRAL) appointed Aurecon to provide consulting services for the improvement of National Route 7 where it crosses the Olifants River near Klawer in the Western Cape. The site is located approximately $300 \mathrm{~km}$ north of Cape Town. The appointment included strengthening, rehabilitation and widening of the existing bridge as well as the design of a new adjacent arch bridge to upgrade the route to a dual carriageway.

The existing bridge, completed in 1957, displayed extensive cracking, failed expansion joints and spall damage to beam soffits. Some columns showed vertical cracks while some foundations presented with horizontal cracks. The arch presented with longitudinal cracks on both the upper and lower surfaces and a previous attempt to fill the cracks proved unsuccessful, as the cracks continued to widen. Figure 1 shows an elevation of the existing arch bridge.

\section{Description of the structure}

The structure consists of a solid arch spanning $92.7 \mathrm{~m}$ across the river with a rise of $14 \mathrm{~m}$. There are $4 \mathrm{x} 14.65$ $\mathrm{m}$ back spans to the north and one $14.65 \mathrm{~m}$ back span to the south giving a total superstructure length of $166 \mathrm{~m}$. The deck cross section over the arch is a $380 \mathrm{~mm}$ thick solid concrete slab section as shown in Figure 2. Before widening the trafficable width was $6.7 \mathrm{~m}$ with a $0.61 \mathrm{~m}$ sidewalk on either side. No shoulders were provided. The arch cross section is a single wide arch with a width of $4.7 \mathrm{~m}$ and a thickness of $1.4 \mathrm{~m}$ rounded at the ends.

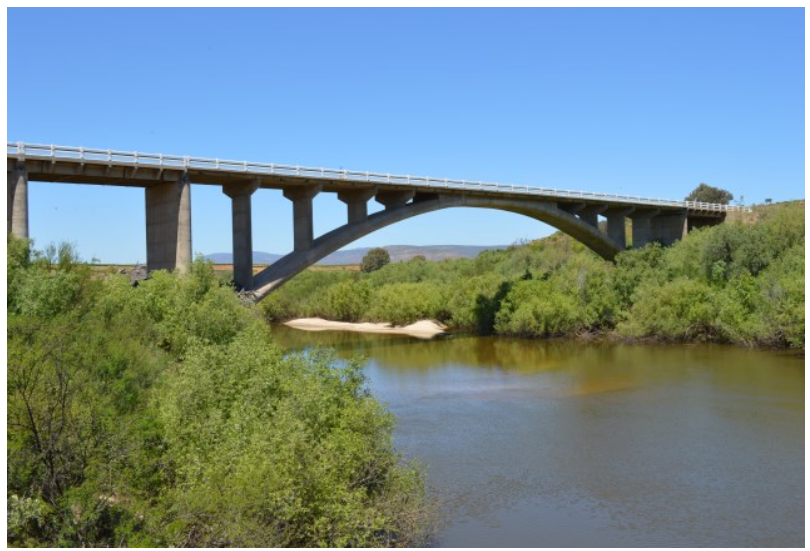

Fig. 1. Elevation of existing bridge.

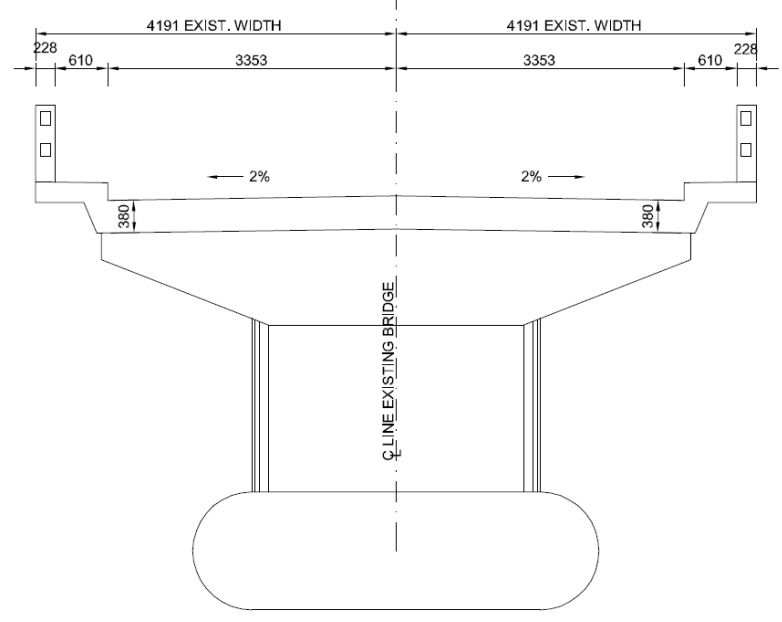

Fig. 2. Deck cross section over arch.

*Corresponding author: pierre.vanderspuy@aurecongroup.com 
The deck cross section on the back spans consists of five precast prestressed T-beams with a $0.15 \mathrm{~m}$ in-situ concrete slab topping as shown in Figure 3. The total deck depth is $1.0 \mathrm{~m}$.

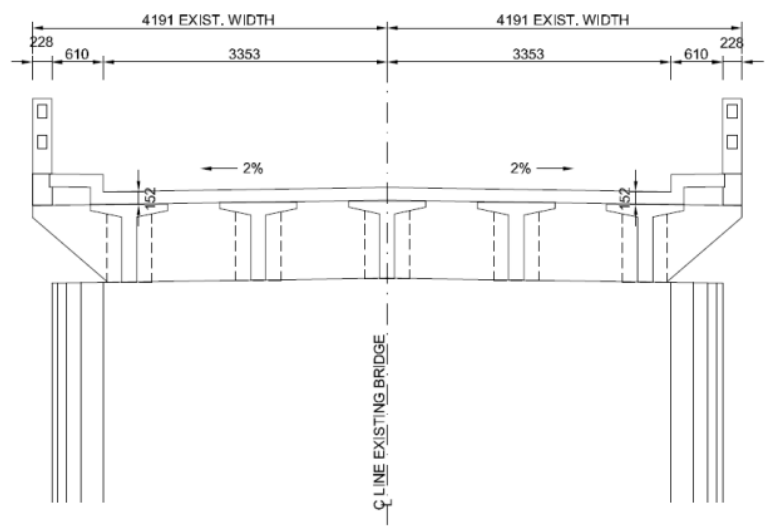

Fig. 3. Deck cross section on back spans.

\section{Construction method}

To explain the behaviour of the bridge it is important to understand the construction methodology. Various methods exist to construct arch bridges of this size. From the as-built drawings it is evident that the Melan method was followed to construct the arch. The method entails the construction of a steel truss arch which is light and easy to erect across a river. Once the steel arch is in place shutters are attached to it and it is encased in concrete. Figure 4 shows an example from the Echelsbacher bridge in Germany. The steel truss is visible and formwork can be seen being attached.

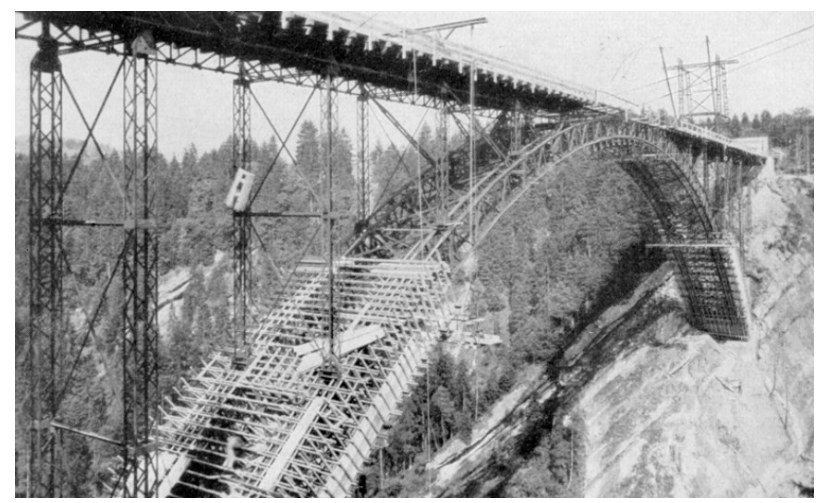

Fig. 4. Echelsbacher bridge in Germany during construction.

The benefit of this method is that the temporary works is utilised as permanent reinforcement for the concrete arch.

Figure 5 shows an as-built cross section through the arch showing the encased steel structure.

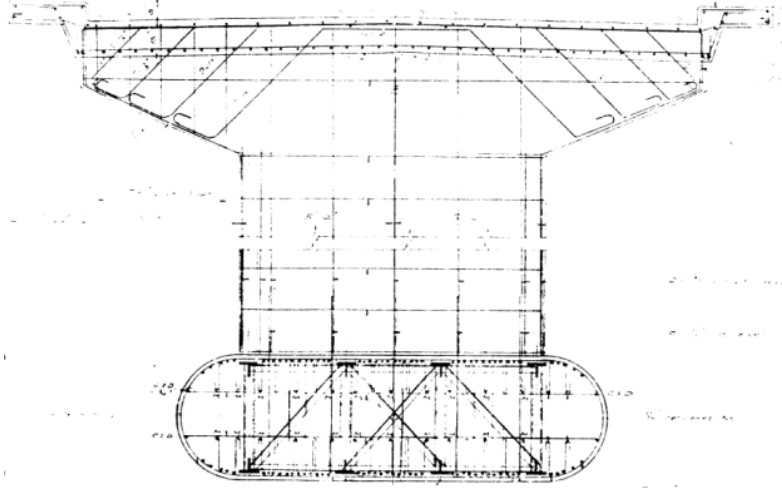

Fig. 5. Section through arch showing steel truss.

\section{Typical defects}

In this section the defects found upon inspection are discussed.

\subsection{Cracking above and below the arch}

Cracks above and below the arch were clearly visible, shown in Figure 6.

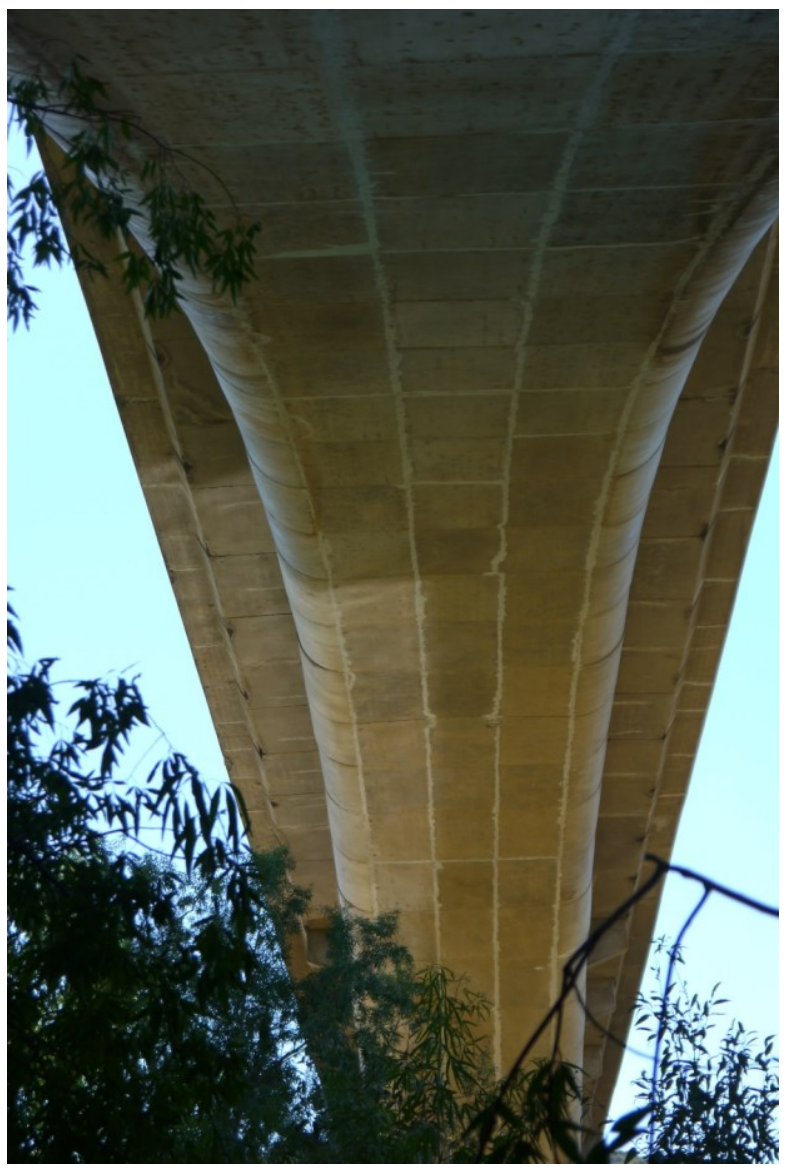

Fig. 6. Longitudinal cracks below arch.

Upon closer inspection it was found that the cracks had previously been filled with a rigid crack filling epoxy material. It is unknown when this repair was performed, but the cracks subsequently continued to open with gaps forming between the epoxy and the 
adjacent concrete, shown in Figure 7. When inspecting the location of the longitudinal truss members in the arch in Figure 5 it is clear that the longitudinal truss elements coincide with the positions of the longitudinal cracks.

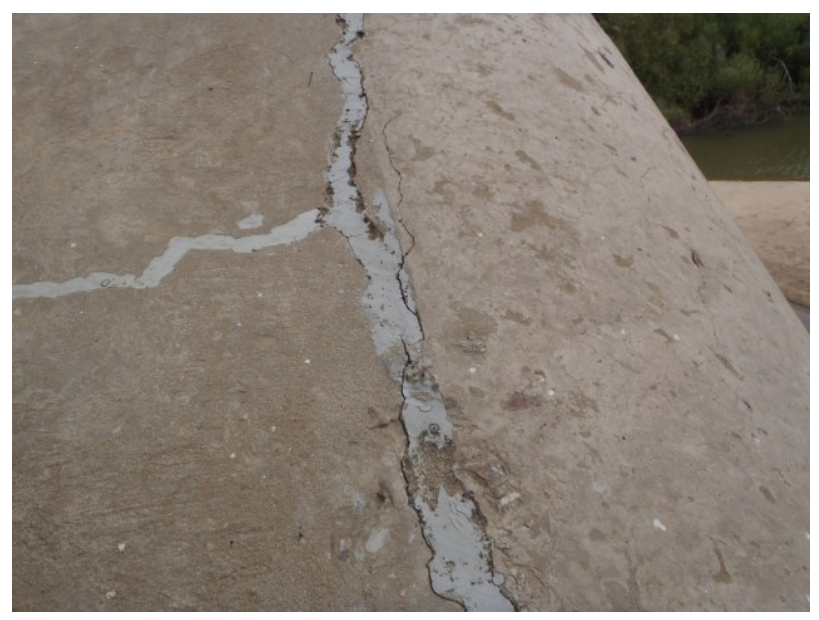

Fig. 7. Arch cracks continued to open.

\subsection{Spalling of beams on back spans}

Isolated incidences of spalling occurred on the precast beams on the back spans, shown in Figure 8. Due to the isolated nature of the occurrences the corrosion of reinforcement was excluded as a possible cause.

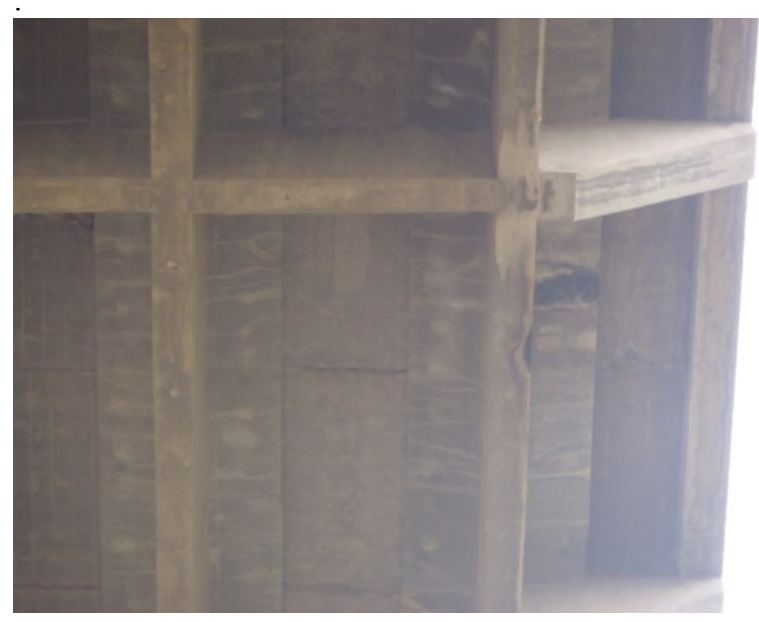

Fig. 8. Beam concrete spalling on back spans.

\subsection{Horizontal cracks in foundations}

Horizontal cracks were observed in pier spread foundations. A typical example of such a crack is shown in Figure 9, indicated with a dark line.

\subsection{Failed expansion joints}

Between the arch and the back spans there are existing claw type joints on both ends of the bridge which have failed (Figure 10). The glands have separated from the claws, letting water and debris into the joint. On the back spans there are clear signs of joint failure judging by the cracks in the asphalt along the joints which are visible on the surface (Figure 11).

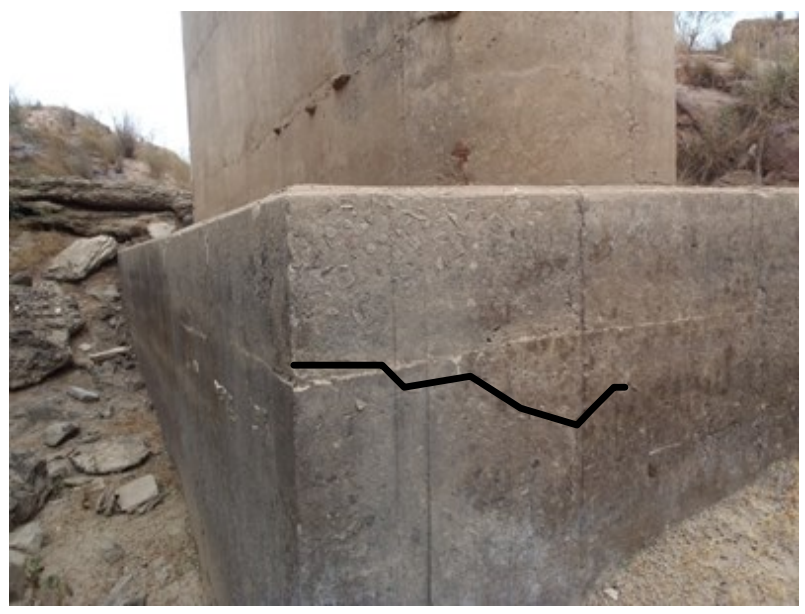

Fig. 9. Horizontal cracks in pier foundations.

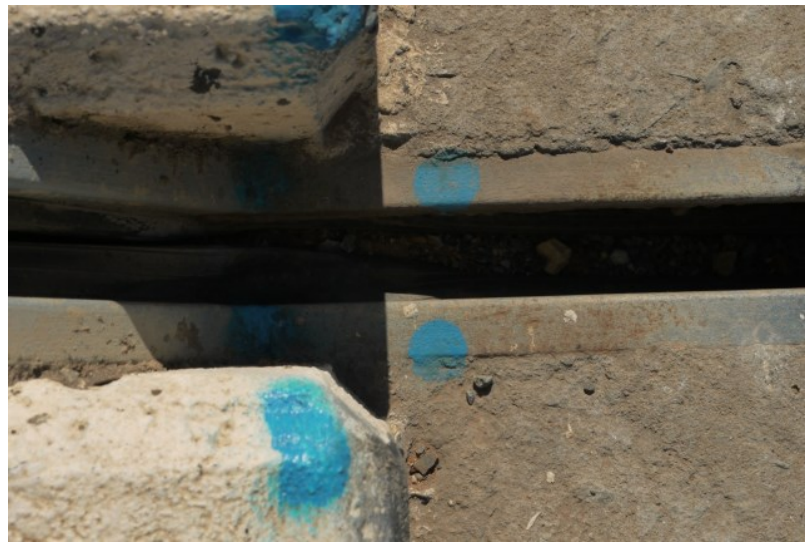

Fig. 10. Failed claw joint.

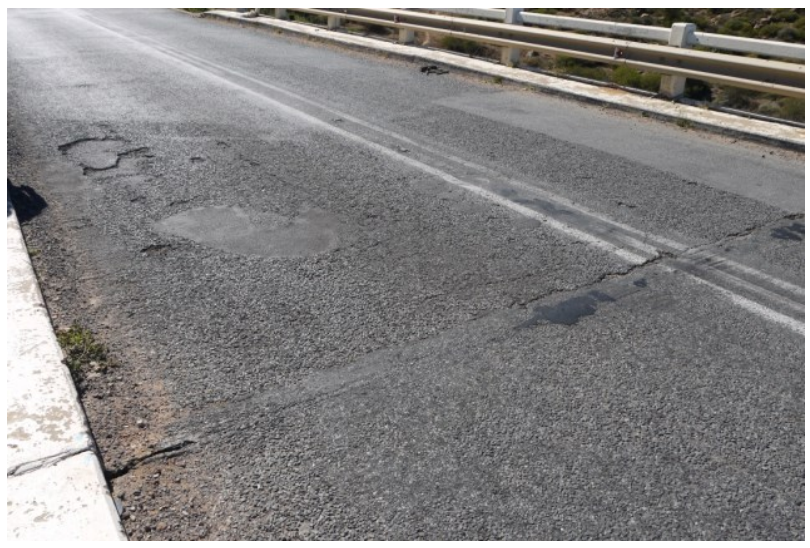

Fig. 11. Failed joint on back spans.

\section{Concrete investigations}

Concern was raised by the client that alkali-silica reaction could be present and that it could be a possible reason for the observed cracking. A concrete material specialist, Cembeton, was appointed to investigate the 
presence of alkali-silica reaction and, if not present, what the reason for the cracking could be.

Nineteen cores were extracted from various locations in the structure and submitted for diagnostic examination. The location of the cores included cores through the cracks in the arch, adjacent to the cracks in the arch, foundations and columns on and off the arch.

The following inspections/tests were performed on the cores:

- Examined with the naked eye and a stereo microscope at low magnification and properties recorded

- $\quad$ Split along their length and carbonation determined with phenolphthalein solution

- Again examined along the split surface with the naked eye and stereo microscope at low magnification and properties recorded, especially paying attention to potentially deleterious mechanisms such as Alkali-Silica Reaction (ASR) and sulphate attack

- Chloride content was determined after extraction with acid using method EN 196-21:1989

- Unconfined compressive strength (UCS) was determined in accordance with South African National Accreditation System (SANAS) specification.

\subsection{Results}

The results of the investigation can be summarised as follows:

a) Visual Inspection

The coarse aggregate was obtained from crushing metaquartzite and occasionally quarzitic sandstone, most probably from the Table Mountain Group. This aggregate is potentially alkali reactive if used with highalkali cement. However, only one core from the top of the arch displayed minor signs of ASR and it could not be concluded that the observed cracking was due to ASR.

The concrete was generally dense and hard and required some effort to split by using a hammer and chisel. Splitting often occurred through the coarse aggregate, indicating good adhesion between aggregate and paste. The concrete was generally well proportioned with a high coarse aggregate content in the case of the arch concrete.

Corrosion of steel reinforcing was observed in a number of the cores and the corrosion was sufficient to cause cracks. Two cores from the column above the arch support and abutment footing respectively contained reinforcement that has suffered substantial section loss.

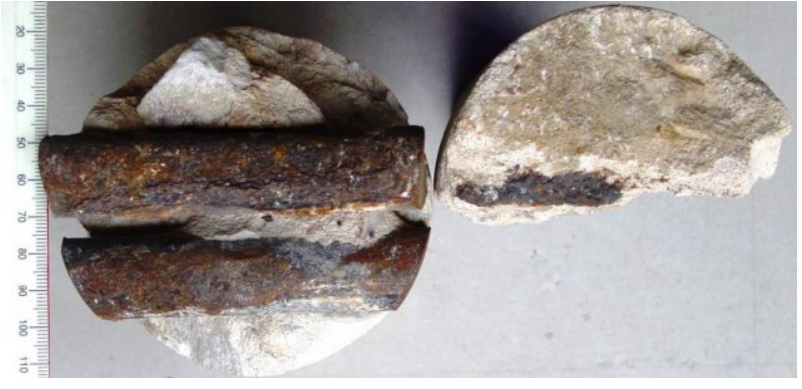

Fig. 12. Corroded reinforcement in core from column above arch support.

b) Cover depth and depth of corrosion

The cover and corrosion depth of various elements are given in Table 1. Note that reinforcement was not present in all cores.

Table 1. Cover and corrosion depth.

\begin{tabular}{|c|c|c|}
\hline Position & Cover $(\mathrm{mm})$ & $\begin{array}{c}\text { Corrosion depth } \\
(\mathrm{mm})\end{array}$ \\
\hline Top of arch & 77 & 77 \\
\hline Column top of arch & 42 & None \\
\hline $\begin{array}{c}\text { Abutment } \\
\text { foundation }\end{array}$ & 75 & 75 \\
\hline Abutment wall & 45 & 75 \\
\hline
\end{tabular}

\section{c) Carbonation}

The carbonation depth varied substantially for the different locations of the bridge and with the exception of the arch, exceeded the cover to the reinforcing steel. Table 2 shows the carbonation depth at various locations.

Table 2. Carbonation depth.

\begin{tabular}{|c|c|}
\hline Position & Carbonation (mm) \\
\hline Top of arch & 4 to 14 \\
\hline Column top of arch & 14 to 35 \\
\hline $\begin{array}{c}\text { Column top of arch } \\
\text { support }\end{array}$ & 40 to 50 \\
\hline $\begin{array}{c}\text { Pier foundation } \\
\text { Abutment wall }\end{array}$ & 47 minimum \\
\hline
\end{tabular}

\section{d) Chloride content}

The acid-soluble content, expressed as a percentage of the concrete is given in Table 3 . The water used to mix 
the concrete is unknown and other reasons for the presence of chloride could not be established.

Table 3. Chloride content.

\begin{tabular}{|c|c|c|}
\hline Position & Depth & $\begin{array}{c}\text { Acid-soluble } \mathrm{Cl}, \%, \\
\text { EN 196-21 1989 }\end{array}$ \\
\hline \multirow{3}{*}{ Top of arch } & 20 to 37 & 0.011 \\
\cline { 2 - 3 } & 37 to 60 & 0.021 \\
\hline \multirow{2}{*}{$\begin{array}{c}\text { Column top of } \\
\text { arch }\end{array}$} & 0 to 15 & 0.018 \\
\cline { 2 - 3 } & 15 to 35 & 0.018 \\
\hline \multirow{3}{*}{$\begin{array}{c}\text { Pier } \\
\text { foundation }\end{array}$} & 0 to 30 & 0.014 \\
\cline { 2 - 3 } & 30 to 60 & 0.010 \\
\cline { 2 - 3 } & 60 to 90 & 0.011 \\
\hline
\end{tabular}

Although the chloride content of the concrete was in some instances close to the limit it was not regarded as enough to have resulted in depassivation of the steel surface.

\section{e) Unconfined Compressive Strength}

The unconfined compressive strength results are given in Table 4.

Table 4. Unconfined compressive strength.

\begin{tabular}{|c|c|}
\hline Position & Strength $(\mathrm{MPa})$ \\
\hline Top of arch & 84.8 \\
\hline Column top of arch & 55.7 \\
\hline $\begin{array}{c}\text { Column top of arch } \\
\text { support }\end{array}$ & 39.9 \\
\hline
\end{tabular}

The strength of the concrete is generally high, especially for the arch. Correlation can also be seen with the depth of carbonation which is less for the higher strength concrete. The design strength of the concrete could not be determined from limited as-built information.

\section{Repair strategy}

\subsection{Longitudinal cracks above and below arch}

The concrete investigation showed that the concrete in the arch was of a very high strength $(84.8 \mathrm{MPa})$ and that the carbonation front has not yet reached the reinforcing steel. Concrete deterioration and steel corrosion was therefore not the cause of the observed cracks. When the construction methodology was considered, it was clear that the cracks coincided with the encased steel trusses. Closer inspection of the as-built drawings also showed that the transverse reinforcement was extremely light with $10 \mathrm{~mm}$ diameter bars spaced at $450 \mathrm{~mm}$. From inspection it was also evident that the cracks were still opening and it was decided to immobilise the movement by transverse strengthening. Strengthening with steel or carbon fibre plates was deemed to be impractical and not very aesthetically pleasing and it was decided to wrap the entire arch in carbon fibre wrapping. The wrapping would prevent the cracks from opening further while an elastic coating was applied over the wrapping to prevent any moisture from reaching the steel. Figure 13 shows the arch after wrapping and coating.

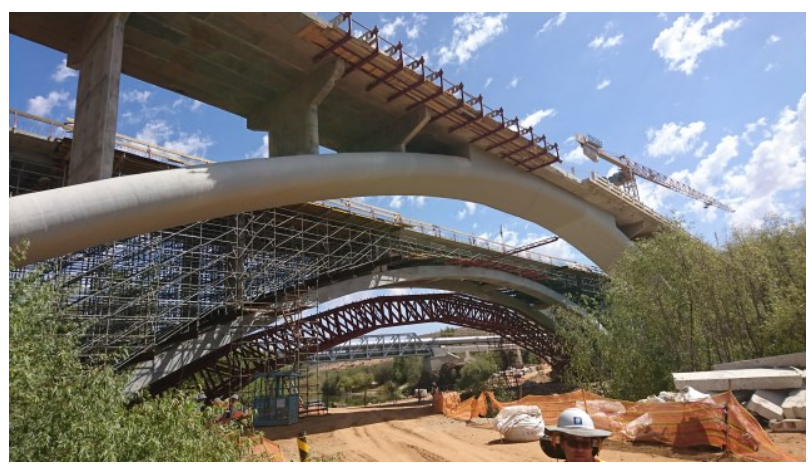

Fig. 13. Wrapped and coated arch.

Glass fibre wrapping was investigated, but found to be not readily available in South Africa.

\subsection{Spalling on precast beams}

Although no testing was performed on the precast beams, they visually appeared to be in a good condition with only local areas of spalling. The spalling of the precast beams was repaired by cutting out to beyond the reinforcement and until sound concrete was reached. The voids were filled with a free flowing low shrinkage grout. Figure 14 shows an example of the spall repair methodology.

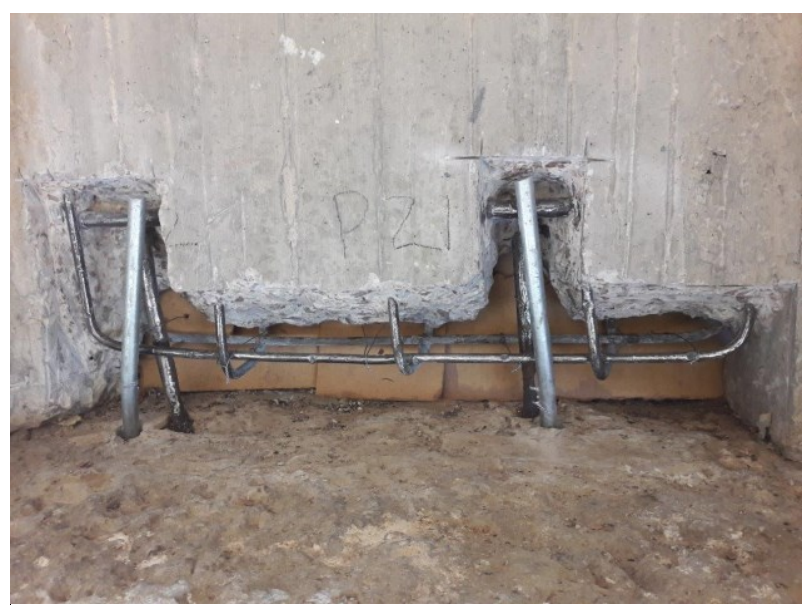

Fig. 14. Beam spall repair.

\subsection{Spalls in columns and abutments}

The concrete in the columns are of a very good quality and only displayed local areas of spalling and corroded reinforcement. It was therefore decided to treat only 
those affected areas. Spalling with corroded reinforcement was treated by removing any loose material, saw cut at right angles to beyond the corroded reinforcement and remove concrete in order to expose full perimeter of bars. The bars were then cleaned to expose sound metal, an anti-corrosive coating applied and a cementitious or polymer modified repair mortar applied. Figure 15 illustrates the procedure that was followed.
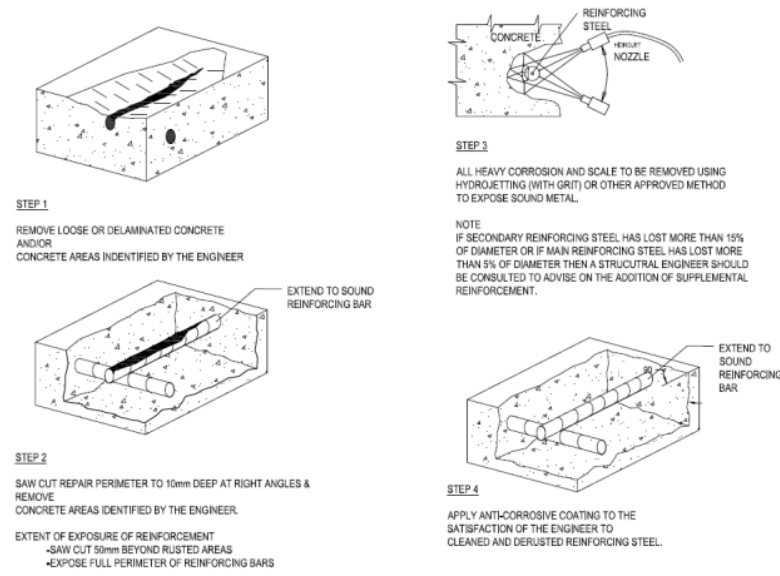

Fig. 15. Column spall repair.

Cracks greater than $0.5 \mathrm{~mm}$ were repaired by means of epoxy injection, shown in Figure 16.

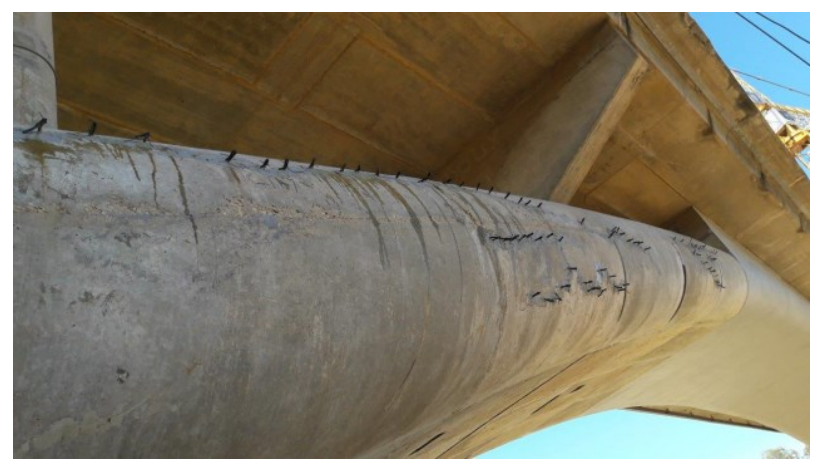

Fig. 16. Injected cracks in arch.

\subsection{Horizontal cracks in pier foundations}

It was clear from the investigation that the concrete quality of the pier foundations was inferior compared to the rest of the structure. The carbonation front has also extended way beyond the reinforcing steel and significant steel corrosion was observed. To prevent further ingress of oxygen and moisture and to replace corroded steel, it was decided to repair the horizontal cracks in pier foundations by encapsulating the affected foundations in a concrete skin. Dowels were drilled into the existing concrete and the concrete surface was scabbled to ensure sufficient bond between old and new concrete. A $250 \mathrm{~mm}$ skin was cast around the existing concrete with its own reinforcement to prevent cracking. The repair was waterproofed around the pier to prevent moisture ingress. Figure 17 shows that crack repair detail.

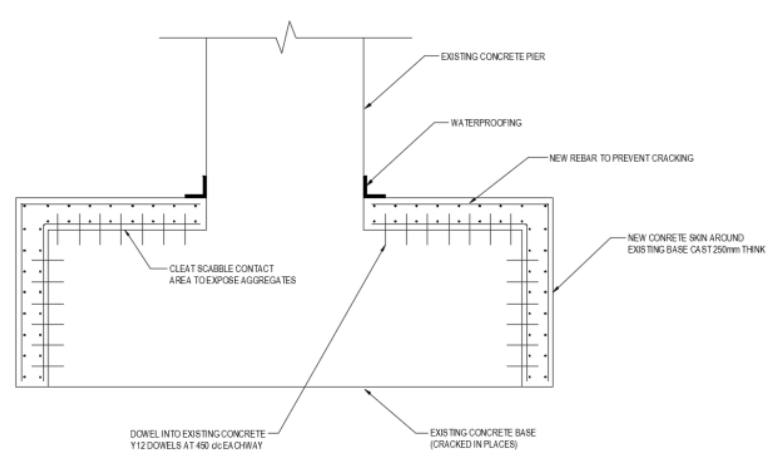

Fig. 17. Foundation crack repair.

\subsection{Expansion joint repair}

The glands on the existing claw type joints above the arch springs had failed and needed to be replaced. They were replaced with new claw type joints with an $80 \mathrm{~mm}$ movement range. Figure 18 shows the repair detail.

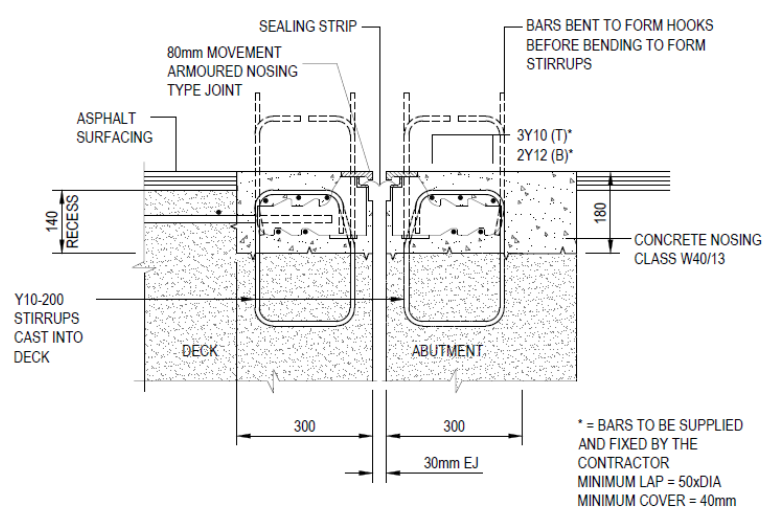

Fig. 18. Claw type joint repair.

The joints on the back spans had polysulfide or silicone seals installed and over time were covered in asphalt during resurfacing projects. After 70 years almost all creep and shrinkage would have taken place and the only movement taken by these joints are temperature fluctuations. Temperature movements were deemed to be less than $10 \mathrm{~mm}$ which made it ideal for the installation of a thorma type joint (Figure 19), otherwise known as an asphaltic plug type joint.

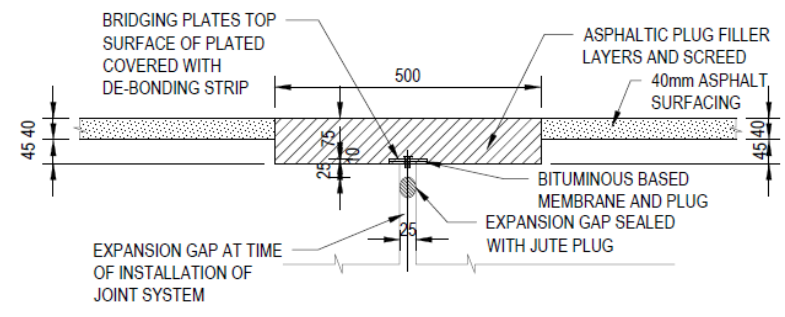

Fig. 19. Asphaltic plug type joint repair. 


\section{Deck widening}

The parapets on the deck consisted of concrete rails and stanchions, which could not resist modern impact loads and they had to be replaced with new concrete parapets. The existing roadway of $6.706 \mathrm{~m}$ wide was also not wide enough to accommodate two lanes of traffic. The edges of the deck, including the existing sidewalks, were demolished and re-cast to produce a slightly wider deck to accommodate the new parapets. A new lightweight pedestrian walkway was added on one side of the deck. The precast beam type deck on the back spans had to be stiffened to accommodate the additional loads and this was done by adding additional transverse beams between the outer two longitudinal beams. The procedure that was followed is illustrated in Figures 20 and 21.

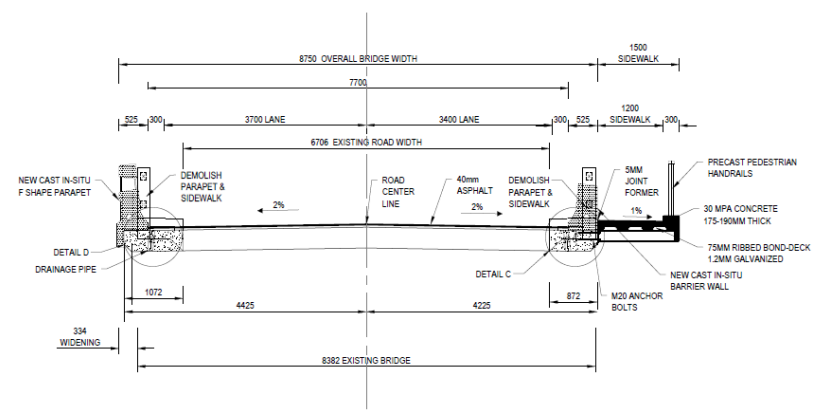

Fig. 20. Typical section of deck over arches.

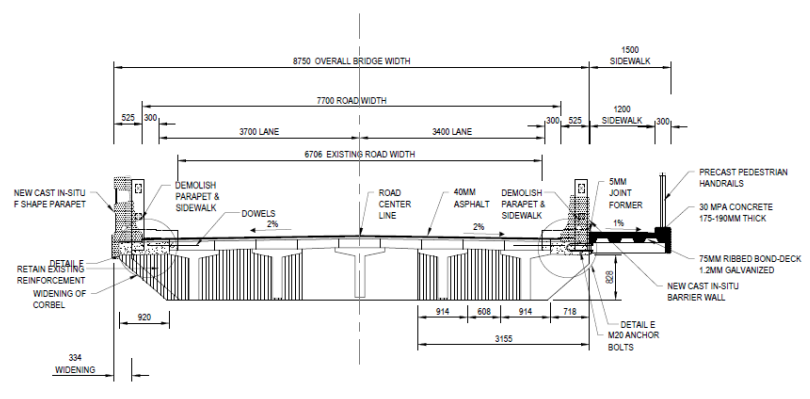

Fig. 21. Typical section of back span deck.

\section{Conclusions}

The existing arch bridge over the Olifants River presented various defects including extensive cracking in various parts of the structure, spall damage and expansion joint failure. This paper describes innovative methods that were employed, including large areas of carbon fibre wrapping, and a novel method of widening the existing deck. Through the use of concrete material specialists and experienced specialist contractors it was possible to meet the client's requirements of extending the service life of the structure. 